\title{
Behavioural response of workers to repeated intergroup encounters in the harvester ant Messor barbarus
}

\author{
G. Birch ${ }^{1} \cdot$ M. A. Cant $^{1} \cdot$ F. J. Thompson ${ }^{1}$ (D)
}

Received: 18 December 2018 / Revised: 29 May 2019 / Accepted: 7 June 2019 / Published online: 19 June 2019

(c) The Author(s) 2019

\begin{abstract}
The evolution of cooperation in animal societies is often associated with the evolution of hostility towards members of other groups. It is usually predicted that groups under attack from outsiders should respond by becoming more cohesive or cooperative. However, the responses of individuals to real or simulated intergroup encounters vary widely, for reasons that are poorly understood. We tested how groups of workers of the harvester ant, Messor barbarus, responded to exposure to members of a different colony versus members of their own colony, and how previous exposure to an intruder affected the intensity of the within-group response. We found that workers increased in activity and had more contact with one another immediately following exposure to an ant from a different colony, but also showed a similar behavioural response to presentations involving an ant from their own colony. However, exposure to an intruder from a different colony resulted in much stronger behavioural responses to a second intruder, encountered shortly afterwards. Our results are consistent with studies of social vertebrates which suggest that exposure to intruders results in increased social cohesion. Our results also show that exposure to an intruder primes group members to respond more strongly to future intrusions. Our findings highlight a disconnect between the assumptions of theoretical models which study the effect of intergroup conflict on social evolution over many generations, and the short-term behavioural responses that are the usual focus of studies of intergroup conflict in insects and vertebrates.
\end{abstract}

Keywords Intergroup conflict · Social evolution · Cohesion · Affiliation · Priming

\section{Introduction}

Intergroup conflict is recognised as a major force influencing selection of social traits in organisms ranging from insects to humans (Darwin 1871; Reeve and Holldobler 2007; Bowles and Gintis 2011; Radford et al. 2016). Theoretical population genetic models have shown how intergroup conflict can favour the spread of altruistic alleles that increase between-group variation in fitness (and hence the strength of between-group selection) relative to within-group variation in fitness (Choi and Bowles 2007; Lehmann and Feldman 2008; Lehmann 2011). In addition, it is widely expected (largely on the basis of empirical studies) that groups under attack from other groups should pull together and become more cooperative (e.g., Radford 2008; Burton-Chellew et al.

F. J. Thompson

F.J.Thompson@exeter.ac.uk

1 Centre for Ecology and Conservation, University of Exeter, Penryn Campus, Penryn, Cornwall TR10 9FE, UK
2010). Thus, conflict between groups is predicted to influence selection for altruism and cooperation within groups on an evolutionary timescale (i.e., over many generations), but is also predicted to affect the immediate, short-term behavioural responses of individuals to each other and to outsiders.

Empirical tests of the prediction that groups under attack from competitors should become more cohesive and cooperative have yielded conflicting results (Radford et al. 2016). For example, several primate species show an increase in grooming following group conflict (Cords 2002; Schino 2007; Majolo et al. 2016), and similar patterns have been observed in green woodhoopoes, Phoeniculus purpureus (Radford 2011) and laboratory groups of cooperative cichlids, Neolamprologus pulcher (Bruintjes et al. 2015). By contrast, in other species such as tufted capuchins, Cebus apella (Polizzi di Sorrentino et al. 2012), vervet monkeys, Chlorocebus aethiops pygerythrus (Arseneau et al. 2015), and bonnet macaques, Macaca radiata (Cooper et al. 2004), 
intergroup conflict has been shown to lead to an increase in within-group aggression.

The wide variation in observed behavioural responses to intergroup conflict may be linked to the inherent heterogeneity of groups in nature (Thompson and Cant 2018). Groups vary in their composition, and group members vary in status and incentive, which can alter decisions of when to fight and the level of response to group conflict (Wilson et al. 2001; Cassidy et al. 2015; Arseneau-Robar et al. 2016). Individuals and groups can also vary in their past experience of conflict, which may differentially change individual responses to threats from competitors (Hsu et al. 2006; Esponda and Gordon 2015; Christensen and Radford 2018).

The ubiquity and intensity of between-group competition in ants make them well suited to testing the effect of past experience on behavioural responses to intergroup conflict (Hölldobler and Wilson 1990; Bourke and Franks 1995; Adams 2016). Previous experimental studies in these systems have focussed on aggressive responses to conflict, with contrasting results. In some species, exposure to other groups resulted in a 'priming' response, where individuals in groups reacted more strongly to future encounters, or underwent developmental changes which increased their ability to fight or defend resources in future. For example, in Argentine ants, Linepithema humile (Van Wilgenburg et al. 2010), workers that were exposed to a non-colony member displayed increased aggression in subsequent encounters, and in interactions with ants from a colony that they had not previously encountered. In the ant Pheidole pallidula, exposure to intergroup conflict led to an increased production of soldiers (Passera et al. 1996). Theoretical and empirical work has shown that past experience can shape individual ants' criteria for non-nestmate recognition which collectively produces an aggressive colony-level response (Newey et al. 2010; Esponda and Gordon 2015). By contrast, some ant species have shown evidence of acclimatisation to the presence of neighbouring competitors, and a reduced aggressive response (Pheidole ants, Langen et al. 2000; Streblognathus peetersi and Plectroctena mandibularis, Tanner and Keller 2012). The causes of these varying responses to recent exposure are unclear. Moreover, in ants, little is known about the effect of exposure to intergroup conflict on social cohesion and within-group affiliation, the types of behaviour on which studies of primates and other vertebrates typically focus.

Here we test how simulated intergroup conflict affects affiliative behaviour and social cohesion in the harvester ant, Messor barbarus, and whether past experience affects the intensity of conflict responses. Specifically, we test the 'primed response' hypothesis which suggests that recent encounters with intruders reflect a high probability of subsequent, potentially costly, encounters. This hypothesis predicts that individuals that are exposed to intruders will exhibit elevated sensitivity and responsiveness to future intrusions, and higher levels of affiliation and social cohesion. We tested these predictions through an experiment in which we repeatedly exposed a group of workers to an individual from their own or an unfamiliar colony.

\section{Methods}

\section{Colony maintenance}

Twenty $M$. barbarus colonies were sourced from commercial suppliers in Spain and the Netherlands (AntHouse, Ants Kalytta, and Ant's Kingdom). Colonies were founded by multiple independent nuptial flights, meaning that relatedness between colonies was unlikely to be high. Colonies were kept in separate darkened nests made of $20 \times 20 \times 3 \mathrm{~cm}$ moulds of plaster of Paris, connected by a tube to a separate clear plastic foraging area, in incubators kept at $25^{\circ} \mathrm{C}$ and with a day-night light regime. Colonies were checked three times a week, and water and food were added when necessary. Colonies contained a queen and individuals belonging to a major caste (the larger size class in the colony) and a minor caste (the smaller size class in the colony). Of the 20 colonies, 16 were used as experimental colonies (average colony size $\pm \mathrm{SE}=20.4$ individuals \pm 1.1 ; average ratio of minor to major caste individuals $\pm \mathrm{SE}=14.6 \pm 0.7)$. Ants from the remaining four colonies (non-experimental colonies) were used as intruder ants in staged encounters with experimental colonies.

\section{Staged experimental encounters}

The behaviour of the 16 experimental colonies was analysed in response to experimental encounters with an intruder individual. Eight ants (one major and seven minors) were randomly selected from the experimental colony and placed into a petri dish. Ants were recorded from above using a Canon DSLR camera and a Panasonic HC-VX980 EB-K camcorder in a dark room under red light. Ants were left for 2 min to acclimatise before the start of the exposure experiment protocol.

After the 2 min acclimatisation period, the ants were recorded for $10 \mathrm{~min}$ to generate baseline measurements of behaviour (the 'before' exposure phase). Ants were then given one of two exposure treatments: exposure to an 'intruder' ant (a randomly selected minor caste ant from one of the non-experimental colonies), or exposure to a 'home' ant (a randomly selected minor caste ant from their own colony). Ants were video recorded for a $10 \mathrm{~min}$ period (the 'during' exposure phase). Exposure to a 'home' ant acted as a matched control to enable us to rule out the possibility that any changes in observed behaviour were the result of an increase in the number of ants in the petri dish, rather 
than the identity of the presented ant. We did not simultaneously expose experimental colonies to multiple presented individuals due to logistical constraints on the size of nonexperimental colonies. The presented ant was marked with a small dot of white enamel paint applied to its head for identification during video analysis.

After 10 min of exposure, the presented ant was removed from the petri dish and ants were video recorded for a further $10 \mathrm{~min}$ period (the 'after' exposure phase). After a $20 \mathrm{~min}$ rest interval, the experiment was repeated to allow us to measure behavioural responses to a second, subsequent intruder. Similarly, the presented ant was either a 'home' ant or an 'intruder' ant. Again, there was a $10 \mathrm{~min}$ period of video recording before, during and after the second exposure. Each experimental colony was exposed to four treatments in total: Intruder-Intruder (II), Intruder-Home (IH), Home-Home (HH), and Home-Intruder (HI). Each experimental colony received the four treatments on separate days and in a randomised order.

\section{Video analysis}

Video footage of behaviour was analysed using PotPlayer version 1.7.13622. We recorded three separate behaviours among ants in the experimental colony: time to first contact, activity, and social contacts. Time to first contact between the presented ant and an ant from the experimental colony (in seconds) was recorded in the 'during' exposure phase as a measure of the strength of response to intruders. We recorded the caste (major or minor) of the ant to make the first contact with the intruder. Activity was measured as the proportion of ants observed moving in the first $20 \mathrm{~s}$ of each minute of the 'before', 'during' and 'after' exposure phases. The number of social contacts was measured as the number of times two ants from the experimental colony touched heads or body parts and was recorded during each minute of the 'before', 'during' and 'after' exposure phases. Cases of grappling (when two ants bite and hold each other with the mandibles) between ants in the experimental colony, and with presented ants were also recorded. However, since grappling was very rare ( 21 observations in 8 out of 16 colonies), it was left out of formal statistical analysis. Observations were not blind to treatment or phase.

\section{Statistical analyses}

Statistical analyses were performed in $\mathrm{R}$ version 3.5.1 ( $\mathrm{R}$ Development Core Team 2016) using linear mixed effects models (LMMs) and generalized linear mixed effects models (GLMMs), with binomial and Poisson error structures and logit and log link functions, respectively, using the 'Ime4' package (Bates et al. 2015). The residuals of LMMs were checked to confirm they were normally distributed with constant variance. For analyses in which the response variable was overdispersed, we used GLMMs fitted with an observational level random effect (Harrison 2014, 2015). In each analysis, we fitted the maximal model including all fixed effects and biologically relevant interactions, along with a random effect of colony ID to account for repeated measures of behaviours from the same experimental colonies. We used likelihood ratio tests to assess the significance of each fixed effect (Bates et al. 2015) and present parameter estimates and standard errors from the maximal model. We did not perform stepwise model reduction by removing non-significant fixed effects from the model due to problems associated with such techniques (Whittingham et al. 2006; Mundry and Nunn 2009; Forstmeier and Schielzeth 2011). However, we did remove non-significant interactions to allow the significance of main effects to be tested (Engqvist 2005). Separate analyses were conducted on behavioural responses to first and second exposures to test for differences in response to intruders compared to home ants (on first exposure), and then for differences in response dependent on the first exposure. Post hoc Tukey's all-pairwise comparisons of means were conducted using the 'glht' function in the 'multcomp' package (Hothorn et al. 2008, 2016) to test for differences between levels of significant main effects of phase ('before', 'during' and 'after'), and treatment in the second exposure (II, IH, HH, $\mathrm{HI})$.

\section{Time to first contact}

In 7 out of 64 cases in the first exposure, and 6 out of 64 cases in the second exposure, contact between an ant from the experimental colony and the presented ant did not occur during the $10 \mathrm{~min}$ exposure period. We therefore removed these trials from our analysis and fitted the logtransformed time to first contact as the response variable in two LMMs (one analysing data from the first exposure, and one analysing data from the second exposure). Time to first contact was log transformed to meet the assumption of normal distribution of residuals. We included treatment (I or $\mathrm{H}$ in the first exposure; II, IH, HH or $\mathrm{HI}$ in the second exposure), the caste of the ant that made the first contact (minor or major), and the interaction between these variables as fixed effects. One trial in the first exposure resulted in contact between a major and minor ant and the presented ant at exactly the same time, and for two trials in the second exposure we were unable to observe the moment of first contact accurately. These trials were subsequently removed from their respective analyses. We fitted these models to data on 56 and 58 trials (for the first and second exposure, respectively) in 16 colonies. 


\section{Activity}

We fitted the proportion of ants from the experimental colony that were active in the first $20 \mathrm{~s}$ after each minute of recording as the response variable in two GLMMs (one analysing data from the first exposure, and one analysing data from the second exposure). We fitted the models using a binomial error structure with an observational level random effect to correct for overdispersion of our response variable (Harrison 2015). We included treatment (I or H in the first exposure; II, IH, HH or $\mathrm{HI}$ in the second exposure), phase (before, during or after), and the interaction between treatment and phase as fixed effects. To test whether activity changed at a different rate between different treatments, we also included time (the minute of recording) and the interaction between time and treatment as additional fixed effects. We fitted these models to data on 1920 min of video recordings in 64 trials in 16 colonies (for both the first and second exposure).

\section{Number of social contacts}

We fitted the number of social contacts occurring between ants in the experimental colony during each minute of recording as the response variable in two GLMMs (one analysing data from the first exposure, and one analysing data from the second exposure). We fitted the models using a Poisson error structure with an observational level random effect to correct for overdispersion of our response variable (Harrison 2014). We included treatment (I or H in the first exposure; II, IH, HH or HI in the second exposure), phase (before, during or after), time (the minute of recording), and the interaction between treatment and phase, and treatment and time as fixed effects. We fitted these models to data on 1920 min of video recordings in 64 trials in 16 colonies (for both the first and second exposure).

\section{Results}

\section{Time to first contact}

We found no evidence that ants responded more quickly to intruder ants than home ants. On first exposure, there was no difference in the time that ants from the experimental colony took to make contact with an intruder ant (mean $\pm \mathrm{SE}=36.9 \pm 19.4 \mathrm{~s})$ compared to a home ant $(m e a n \pm \mathrm{SE}=62.8 \pm 42.4 \mathrm{~s})$. Nor was there any difference in the reaction of minor ants (mean $\pm \mathrm{SE}=39.7 \pm 20.0 \mathrm{~s}$ ) and major ants (mean $\pm \mathrm{SE}=74.6 \pm 63.4 \mathrm{~s}$ ) to the presented ant (GLMM, treatment $\times$ caste: $\chi_{1}^{2}=0.25, P=0.62$; treatment: $\chi_{1}^{2}=0.63, P=0.43$; caste: $\chi_{1}^{2}=0.43, P=0.51$; model intercept $\pm \mathrm{SE}=3.35 \pm 0.38$ ). We also found no evidence that

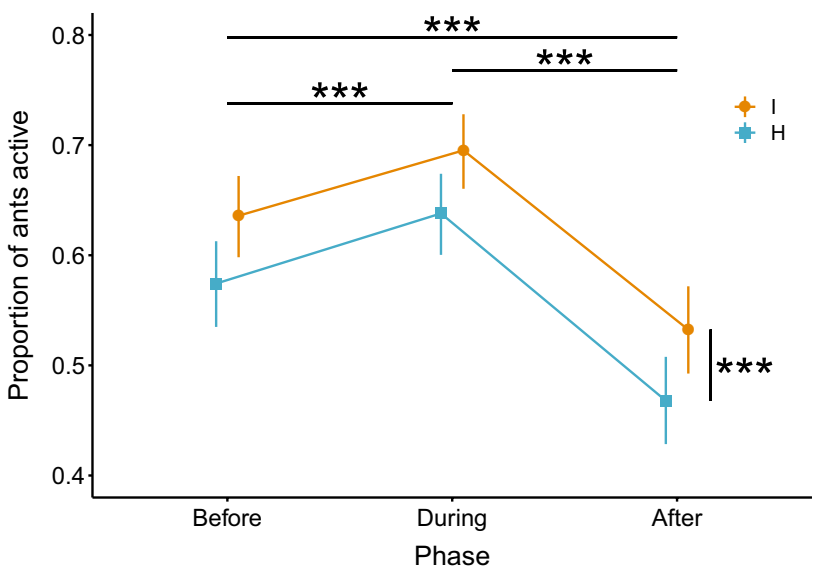

Fig. 1 The effect of treatment on the proportion of ants active during the first $20 \mathrm{~s}$ of each minute in each phase of the first exposure $(N=1920 \mathrm{~min}$ in 64 trials in 16 colonies). Points show predicted means from a GLMM \pm SE. In the first exposure, ants significantly increased in activity when presented with an intruder ant (I), but they also showed a similar behavioural response when presented with a home ant $(\mathrm{H})$. Asterisks refer to post hoc Tukey's all-pairwise comparisons of means. $* * * P<0.001$

ants reacted differently to a second intruder ant depending on their previous experience. During the second exposure, there was no difference in time to first contact with the presented ant for castes in different treatments (GLMM, treatment $x$ caste: $\beta \pm \mathrm{SE}=-1.92 \pm 1.45, \chi_{1}^{2}=1.71, P=0.19$ ). Ants did not react differently depending on whether they had previously been exposed to an intruder or a home ant (mean \pm SE seconds for treatments: $\mathrm{II}=25.7 \pm 17.9$; $\mathrm{HI}=23.5 \pm 8.3 ; \mathrm{IH}=51.4 \pm 36.6 ; \mathrm{HH}=95.5 \pm 81.0 ; \mathrm{GLMM}$, treatment: $\left.\chi_{1}^{2}=7.06, P=0.07\right)$. There was also no difference in response time of minor ants (mean $\pm \mathrm{SE}=51.4 \pm 25.9 \mathrm{~s}$ ) and major ants (mean $\pm \mathrm{SE}=29.3 \pm 28.5 \mathrm{~s}$; GLMM, caste: $\left.\beta \pm \mathrm{SE}=0.60 \pm 0.66, \chi_{1}^{2}=0.81, P=0.37\right)$.

\section{Activity}

In the first exposure, ants from the experimental colony were significantly more active when presented with an intruder ant compared to a home ant (GLMM, $\beta \pm \mathrm{SE}=0.26 \pm 0.04$, $\chi_{1}^{2}=37.24, P<0.001$; Fig. 1). Phase of exposure also had a significant effect on ant activity $\left(\chi_{2}^{2}=178.74\right.$, $P<0.001$; Fig. 1), but this effect was independent of treatment (treatment x phase: $\chi_{2}^{2}=4.68, P=0.097$; Fig. 1). Ants were significantly more active during exposure to the presented ant than in the 'before' or 'after' phases (post hoc Tukey's test, 'before' vs 'during': $\beta \pm \mathrm{SE}=$ $0.27 \pm 0.052, z=5.14, P<0.001$; 'during' vs 'after': $\beta \pm \mathrm{SE}=-0.70 \pm 0.052, z=-13.39, P<0.001$; 'before' vs 'after': $\beta \pm \mathrm{SE}=-0.43 \pm 0.051, z=-8.36, P<0.001$; Fig. 1). Ant activity decreased significantly during each 


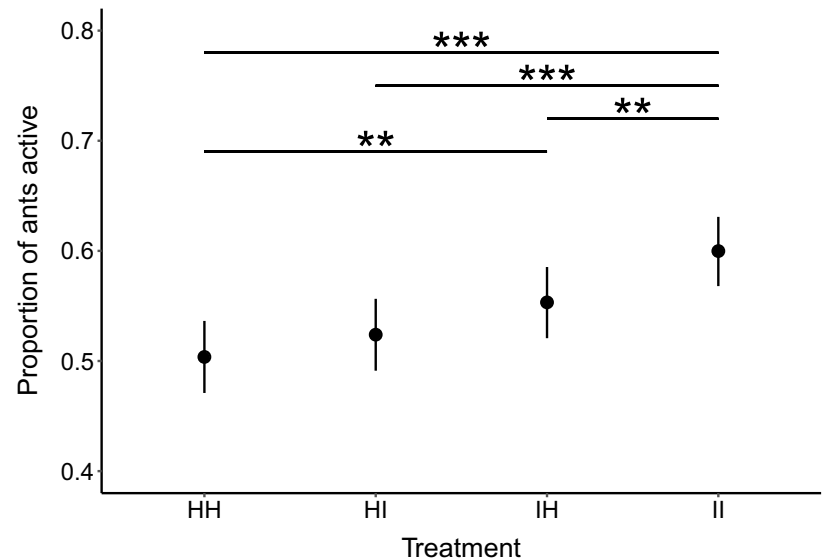

Fig. 2 The effect of treatment on the proportion of ants active during the first $20 \mathrm{~s}$ of each minute in each phase of the second exposure ( $N=1920 \mathrm{~min}$ in 64 trials in 16 colonies). Points show predicted means from a GLMM \pm SE. In the second exposure, ants showed a primed response if they had been exposed to an intruder ant in the first exposure (IH, II) compared to a home ant (HI, HH). Asterisks refer to post hoc Tukey's all-pairwise comparisons of means. $* * * P<0.001, * * P<0.01$. Non-significant pairwise comparisons are not labelled

trial $\left(\beta \pm \mathrm{SE}=-0.071 \pm 0.007, \chi_{1}^{2}=91.97, P<0.001\right)$, but this effect was independent of treatment (treatment $\times$ time: $\chi_{1}^{2}=0.027, P=0.87$ ).

In the second exposure, we found evidence of a primed response in the activity of experimental ants (GLMM, treatment: $\left.\chi_{3}^{2}=46.11, P<0.001\right)$. Ants that had previously been exposed to an intruder ant were significantly more active than ants that had been previously exposed to a home ant, although the comparison between IH and HI treatments was not significant (post hoc Tukey's test, HI vs II: $\beta \pm \mathrm{SE}=0.31 \pm 0.061, z=5.086, P<0.001 ; \mathrm{HH}$ vs II: $\beta \pm \mathrm{SE}=0.39 \pm 0.061, z=6.41, P<0.001$; HH vs $\mathrm{IH}: \beta \pm \mathrm{SE}=0.20 \pm 0.061, z=3.29, P=0.0054$; HI vs IH: $\beta \pm \mathrm{SE}=0.12 \pm 0.061, z=1.95, P=0.21$; Fig. 2). Ants that had been previously exposed to an intruder ant were also significantly more active when subsequently presented with an intruder compared to a home ant (IH vs II: $\beta \pm \mathrm{SE}=0.19 \pm 0.06, z=3.17, P=0.0087$; Fig. 2 ), but not when they were previously exposed to a home ant (HH vs HI: $\beta \pm \mathrm{SE}=0.081 \pm 0.061, z=1.33, P=0.54$; Fig. 2 ). Consistent with the first exposure, ants were also significantly more active in the 'during' phase than in the 'before' or 'after' phase $\left(\chi_{2}^{2}=337.38, P<0.001\right.$; post hoc Tukey's test, 'before' vs 'during' $\beta \pm \mathrm{SE}=0.99 \pm 0.053, z=18.72, P<0.001$; 'during' vs 'after': $\beta \pm \mathrm{SE}=-0.58 \pm 0.052, z=-11.16$, $P<0.001$; 'before' vs 'after' $\beta \pm \mathrm{SE}=0.41 \pm 0.053$, $z=7.76, P<0.001$; Fig. 3). However, the effect of treatment and phase was independent of one another (treatment $\times$ phase: $\chi_{6}^{2}=11.22, P=0.082$ ). Similar to the first exposure, ant activity decreased significantly during each trial of the second exposure $\left(\beta \pm \mathrm{SE}=-0.065 \pm 0.007, \chi_{1}^{2}=73.94\right.$, $P<0.001)$, and this effect was independent of treatment (treatment $\times$ time: $\chi_{3}^{2}=2.97, P=0.40$ ).

\section{Number of social contacts}

In the first exposure, we observed significantly more social contacts between ants from the experimental colony when they were exposed to an intruder ant compared to a home ant (GLMM, $\beta \pm \mathrm{SE}=0.18 \pm 0.02, \chi_{1}^{2}=59.26$, $P<0.001$; Fig. 4), but there was no significant difference between treatments across phases (treatment $\mathrm{x}$ phase: $\chi_{2}^{2}=1.52, P=0.47$; Fig. 4). Independent of treatment, the phase had a significant effect on the number of social contacts $\left(\chi_{2}^{2}=20.49, P<0.001\right)$ with significantly fewer contacts after exposure compared to before and during exposure (post hoc Tukey's test, 'before' vs 'during': $\beta \pm \mathrm{SE}=0.047 \pm 0.028, z=1.71, P=0.20$; 'during' vs 'after': $\beta \pm \mathrm{SE}=-0.13 \pm 0.028, z=-4.53$, $P<0.001$; 'before' vs 'after' $\beta \pm \mathrm{SE}=-0.079 \pm 0.028$,
Fig. 3 The effect of phase on the proportion of ants active during the first $20 \mathrm{~s}$ of each minute $(N=1920 \mathrm{~min}$ in 64 trials in 16 colonies for both the first and second exposure). Points show predicted means from a GLMM \pm SE. Activity peaked during exposure to the presented ant in both the first and second exposure. Asterisks refer to post hoc Tukey's allpairwise comparisons of means. $* * * P<0.001$

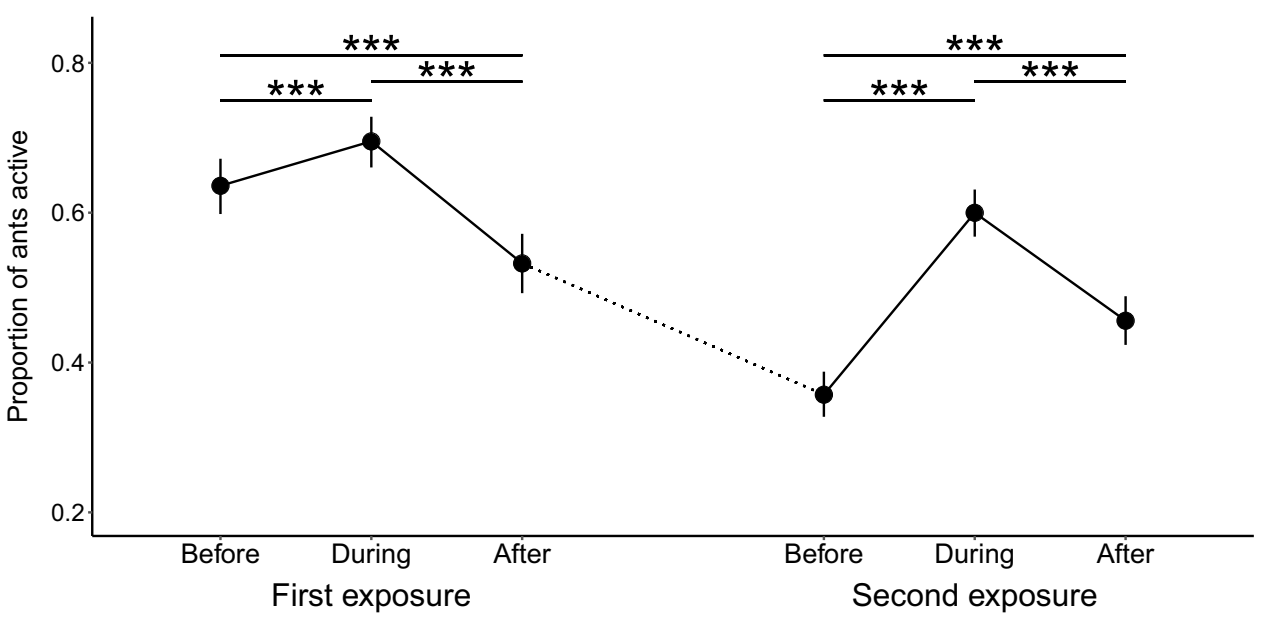




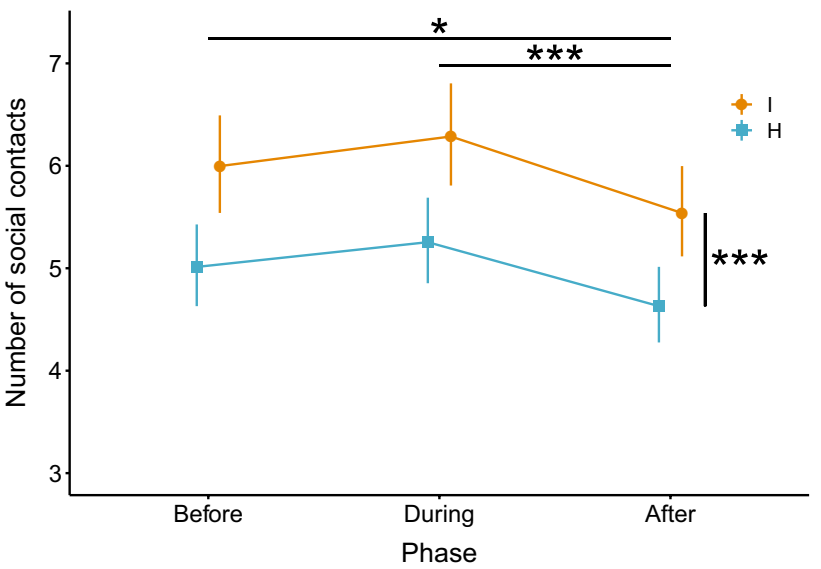

Fig. 4 The effect of treatment on the number of social contacts between ants in the experimental colony during each minute of each phase of the first exposure $(N=1920 \mathrm{~min}$ in 64 trials in 16 colonies). Points show predicted means from a GLMM \pm SE. In the first exposure, ants performed significantly more social contacts when presented with an intruder ant (I), but they also showed a similar behavioural response when presented with a home ant $(\mathrm{H})$. Asterisks refer to post hoc Tukey's all-pairwise comparisons of means. $* * * P<0.001, * P<0.05$. Non-significant pairwise comparisons are not labelled

$z=-2.82, P=0.013$; Fig. 4). Ants made significantly fewer social contacts through the course of each trial, but this effect was not dependent on treatment (treatment $\times$ time: $\chi_{1}^{2}=1.70, P=0.19$; time: $\beta \pm \mathrm{SE}=-0.063 \pm 0.004$, $\chi_{1}^{2}=236.44, P<0.0001$ ).

Consistent with our findings of a primed response in the activity of experimental ants, we also found that the number of social contacts between ants was significantly different depending on whether they had previously been exposed to an intruder or a home ant (GLMM, treatment: $\left.\chi_{3}^{2}=72.31, P<0.0001\right)$. Ants that had previously been presented with an intruder ant made significantly more social contacts than ants that had been exposed to a home ant (post hoc Tukey's test, HI vs II: $\beta \pm \mathrm{SE}=0.24 \pm 0.04$, $z=6.03, P<0.001$; HH vs II: $\beta \pm \mathrm{SE}=0.33 \pm 0.041$, $z=8.21, P<0.001$; HH vs $\mathrm{IH}: \beta \pm \mathrm{SE}=0.20 \pm 0.041$, $z=4.81, P<0.001$; HI vs IH: $\beta \pm \mathrm{SE}=0.11 \pm 0.041$, $z=2.60, P=0.046$; Fig. 5). Ants that had been exposed to an intruder ant in the first exposure made significantly more social contacts when they were subsequently presented with an intruder compared to a home ant (IH vs II: $\beta \pm \mathrm{SE}=0.14 \pm 0.039, z=3.43, P=0.0034$; Fig. 5 ), but this difference was not observed when the first exposure was to a home ant (HH vs HI: $\beta \pm \mathrm{SE}=0.093 \pm 0.042$, $z=2.21, P=0.12$; Fig. 5). The phase had a significant effect on the number of social contacts $\left(\chi_{2}^{2}=195.31\right.$, $P<0.001)$, but this was not dependent on treatment (treatment $\times$ phase: $\chi_{6}^{2}=3.98, P=0.68$ ). Ants made significantly more contacts during exposure to the presented

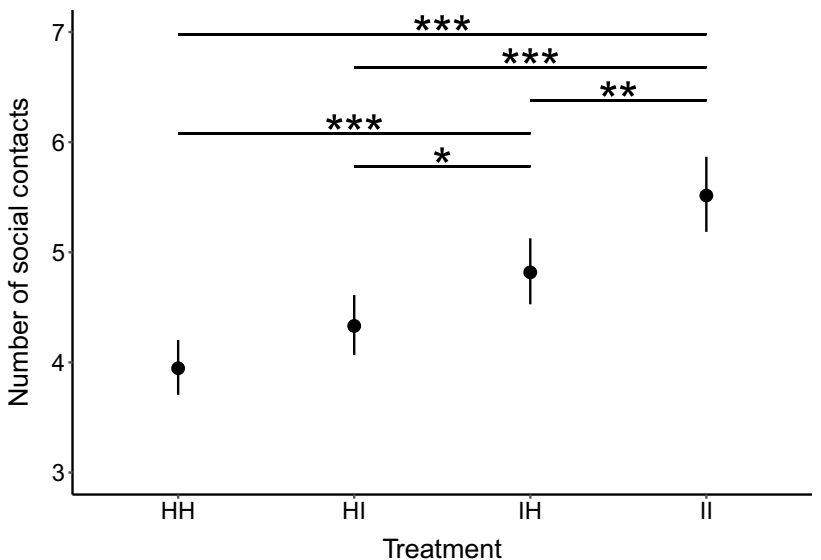

Fig. 5 The effect of treatment on the number of social contacts between ants in the experimental colony during each minute of each phase of the second exposure $(N=1920 \mathrm{~min}$ in 64 trials in 16 colonies). Points show predicted means from a GLMM \pm SE. In the second exposure, ants showed a primed response if they had been exposed to an intruder ant in the first exposure (IH, II) compared to a home ant $(\mathrm{HI}, \mathrm{HH})$. Asterisks refer to post hoc Tukey's all-pairwise comparisons of means. $* * * P<0.001, * * P<0.01, * P<0.05$. Non-significant pairwise comparisons are not labelled

ant compared to before, and this effect lasted throughout the 'after' exposure phase (post hoc Tukey's test, 'before' vs 'during': $\beta \pm \mathrm{SE}=0.51 \pm 0.036, z=14.35, P<0.001$; 'during' vs 'after': $\beta \pm \mathrm{SE}=-0.19 \pm 0.034, z=-5.67$, $P<0.001$; 'before' vs 'after': $\beta \pm \mathrm{SE}=0.32 \pm 0.037$, $z=8.78, P<0.001$; Fig. 6). Ants made significantly fewer social contacts through each trial of the second exposure $\left(\beta \pm \mathrm{SE}=-0.083 \pm 0.005, \chi_{1}^{2}=247.67, P<0.001\right)$, and this effect was independent of treatment (treatment $\times$ time: $\left.\chi_{3}^{2}=0.39, P=0.94\right)$.

\section{Discussion}

Our study shows that workers of the harvester ant M. barbarus respond to the presence of an intruder by increasing their activity patterns overall and in particular by increasing the rate at which they make contact with other colony members. This is consistent with the hypothesis that individual workers act to increase coordination or cohesiveness among members of their own group when confronted by members of a different group, which may serve as an indicator of invasion or attack by another colony. However, the behavioural response was statistically similar regardless of whether the presented ant was from their own colony or from a different colony, suggesting that when the ants first encountered an unfamiliar individual, they made no obvious distinction between members of their own or other colonies. Nevertheless, exposure to an unfamiliar intruder did have a large influence on the response of ants to a second intruder 


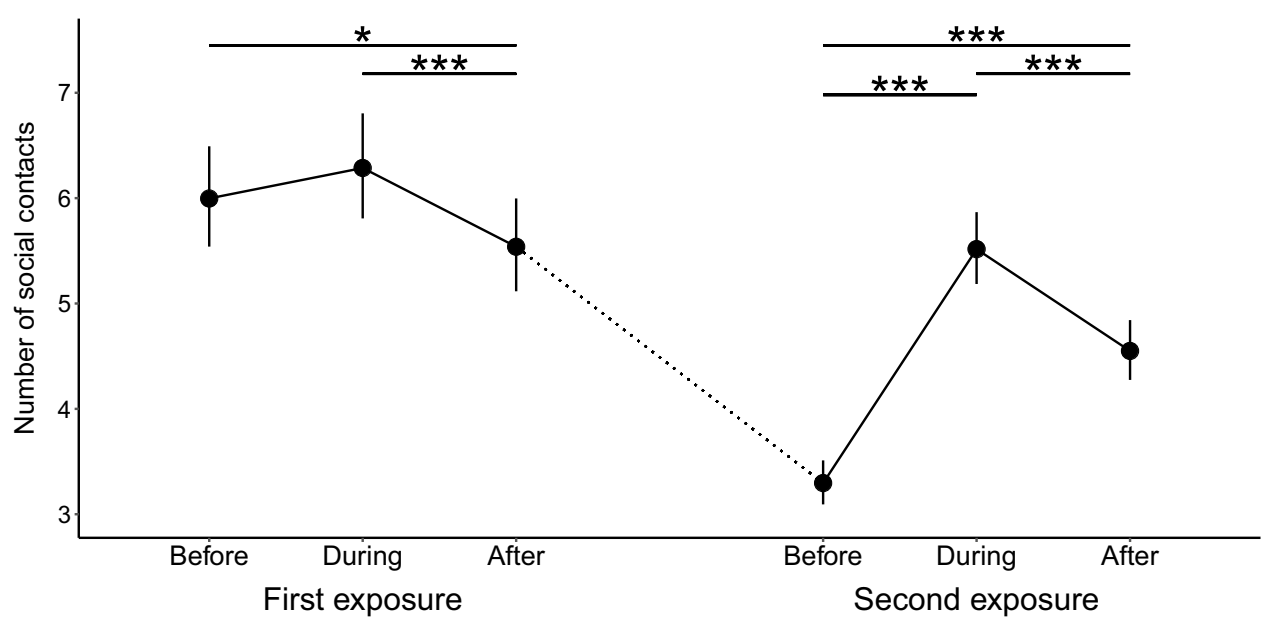

Fig. 6 The effect of phase on the number of social contacts between ants during each minute $(N=1920 \mathrm{~min}$ in 64 trials in 16 colonies for both the first and second exposure). Points show predicted means from a GLMM \pm SE. The number of social contacts was not different during exposure to the presented ant compared to before exposure in

encountered shortly afterwards. Specifically, an encounter with an intruder from a different colony primed the ants to respond more strongly to a second intruder, particularly when the second intruder was also from a different colony. Thus, our results suggest that recent previous experience of potential intergroup conflict increases the within-group response to a simulated intrusion, in line with the 'primed response' hypothesis.

These findings in a eusocial insect offer a complement to research on the behavioural responses of some social vertebrates to simulated intrusions. For example, in cooperative cichlids, $N$. pulcher, laboratory groups that are exposed to intruders subsequently engage in elevated rates of affiliative behaviour (e.g., soft touching and following; Bruintjes et al. 2015). A similar increase in affiliative behaviour following exposure to experimental intruders has been shown in green woodhoopoes (Radford 2008). In both cases, the increase in affiliative behaviour is interpreted as an adaptive response which increases group cohesion, protecting the group from future attacks. These systems differ from our ants in that group members each have the potential to reproduce, either currently or in the future, whereas the ant workers are selected to behave in a way that maximises their indirect component of fitness, realised via the assistance they can provide to the colony production of reproductives. The fact that similar behavioural responses to intruders are seen in such different systems is consistent with the hypothesis that increased contact or affiliation among group members serves to prepare or strengthen the group against future attacks, and is therefore favoured by both selection acting at the level of the individual and the level of the group (Okasha 2006; Robinson and Barker 2017). Unlike the findings on cooperative the first exposure, but peaked during exposure to the presented ant in the second exposure. Asterisks refer to post hoc Tukey's all-pairwise comparisons of means. $* * * P<0.001, * P<0.05$. Non-significant pairwise comparisons are not labelled

vertebrates, however, our study suggests that harvester ants respond to their first encounter with an unexpected individual in a similar way, without making distinctions based on colony of origin.

We found evidence that the response to intruders in $M$. barbarus, in the form of social contacts and activity, was enhanced by previous experience of an encounter with a non-colony intruder. This result suggests that $M$. barbarus workers utilise experience of past enemy encounters to calibrate future behavioural responses, in line with previous evidence in a variety of taxa (Rose and Brenowitz 1997; Monclús et al. 2014), including other ant species (Thomas et al. 2007; Newey et al. 2010; Van Wilgenburg et al. 2010; Adams 2016). This result also provides support for predictions of recent theory which shows that individual past experience results in quicker and more accurate recognition of non-nestmates at the colony (Esponda and Gordon 2015). Ants could collectively gain experience of enemy cuticular hydrocarbons (CHCs) used in nestmate discrimination during first exposure which primes them to respond more intensely to non-nestmates on subsequent exposure (Guerrieri et al. 2009; Newey et al. 2010). Initial exposure to an intruder ant could affect patterns of movement (e.g., by eliciting a patrolling response) and the structure of social networks, such that subsequent encounters between ants in the colony are more likely. For example, an intruder ant could represent a pathogenic threat to the colony that stimulates a change in within-colony social dynamics (Stroeymeyt et al. 2018). Encounters with an intruder, even a single intruder as in our experiment, may result in a step change in the perceived level of risk of intergroup competition or attack. In addition, the response of individuals to simulated intrusion 
may depend on the number of intruders or the perceived strength or composition of a group of intruders (Roulston et al. 2003). Similarly, intruders could represent a larger threat if they are more likely to be of a more aggressive phenotype (Sturgis and Gordon 2013). The question of how groups assess each other's relative strength and motivation has been little explored theoretically or empirically. In contrast to dyadic animal contest theory, signals of resource holding potential (RHP) of groups depend on the individual and combined signalling effort of individual group members, which may vary in complex (non-linear) ways with group size and composition. Experimental approaches in ant systems such as ours could be a powerful tool to elucidate some of the principles of intergroup signalling and conflict, and how group size and individual RHP combine to determine group RHP (e.g., Batchelor et al. 2012).

There are some limitations to our study which should be considered when interpreting our results. First, we observed fewer social contacts and a lower proportion of active ants in the 'before' phase of the second exposure compared to the 'before' phase of the first exposure. This unexpected difference in behaviour could reflect a lack of acclimatisation to the assay arena (itself an artificial environment) before the first exposure, or fatigue from responding to the previously presented ant before the second exposure. Fatigue in response to stimuli makes direct comparisons between initial and subsequent exposures more difficult to interpret, but does not detract from our observed effect of a primed response to an intruder. In fact, we might have observed an even stronger primed response in the second exposure had ants not been fatigued. Second, colony sizes used in our experiments were small. This may have affected colony response behaviour to intruders and could go some way to explaining the lack of observed aggression to presented ants, particularly in light of evidence that colony-level responses to non-nestmates are highly dependent on combined individual-level experience and behaviour (Guerrieri et al. 2009; Newey et al. 2010; Esponda and Gordon 2015). Similarly, we cannot rule out that the presentation of a single intruder may not elicit a behavioural response that accurately reflects the response of the colony as a whole (Roulston et al. 2003). Finally, we did not conduct behavioural assays blind to treatment. Non-blind studies are exposed to potentially inflated effect sizes (van Wilgenburg and Elgar 2013) and, as such, although our results provide evidence in support of a primed response to intruders, we should exercise some care when determining the certainty of our results.

Studies that show increased affiliative behaviour in response to simulated or real intergroup encounters are often taken as consistent with the predictions of theoretical models of the role of intergroup conflict as a promoter of cooperation and altruism within groups. However, there is currently a disconnect between theory and data on this point.
Most formal population genetic and game theoretical models of intergroup conflict examine changes in the frequency, over many generations, of fixed genetic traits that influence behaviour toward members of a different group versus members of the own group (e.g., 'parochialism' and 'altruism', Choi and Bowles 2007; or 'belligerence' and 'bravery', Lehmann and Feldman 2008). These models do not analyse how individuals should respond plastically to changes in their social environment. The expectation that groups under attack should pull together and behave more cohesively is derived largely from verbal reasoning (starting with Darwin 1871), or empirical observations in humans and non-human animals (Radford et al. 2016; Kavaliers and Choleris 2017). Our findings are consistent with this expectation, but also draw further attention to this current disconnect between the assumptions of current theory and the types of behavioural responses that are measured in empirical studies. In particular, our behavioural results highlight the need for models which specify precisely what fitness benefit individuals and groups derive from behaviour that is determined to be affiliative (such as grooming or allopreening), and how this fitness benefit is realised. For example, does increased grooming among members of a primate group increase group cohesion through a process of reciprocity? Does increased social contact among worker ants communicate information on group strength, or motivation and readiness to fight? New theoretical models which make explicit assumptions about the nature of intergroup competition and the function of within-group affiliation may help to explain why, in some circumstances, intergroup conflict (whether real or simulated) leads to increased social cohesion (this study; Cords 2002; Bruintjes et al. 2015), whereas in others it appears to exacerbate internal tensions (Cooper et al. 2004; Polizzi di Sorrentino et al. 2012; Arseneau et al. 2015).

Acknowledgements We thank Nicole Goodey for donating ant colonies to use in this study. We also thank Jeremy Field for practical assistance and helpful discussion, and two anonymous referees for their useful comments on the manuscript. Funding was provided by a Natural Environment Research Council grant no. NE/S000046/1 to M.A.C and F.J.T. Data is available from the corresponding author on request.

Open Access This article is distributed under the terms of the Creative Commons Attribution 4.0 International License (http://creativeco mmons.org/licenses/by/4.0/), which permits unrestricted use, distribution, and reproduction in any medium, provided you give appropriate credit to the original author(s) and the source, provide a link to the Creative Commons license, and indicate if changes were made.

\section{References}

Adams ES (2016) Territoriality in ants (Hymenoptera: formicidae): a review. Myrmecol News 23:101-118. https://doi. org/10.1016/0095-8956(72)90015-9 
Arseneau TJM, Taucher AL, van Schaik CP, Willems EP (2015) Male monkeys fight in between-group conflicts as protective parents and reluctant recruits. Anim Behav 110:39-50. https://doi. org/10.1016/j.anbehav.2015.09.006

Arseneau-Robar TJM, Taucher AL, Müller E et al (2016) Female monkeys use both the carrot and the stick to promote male participation in intergroup fights. Proc R Soc Lond B Biol Sci. https://doi. org/10.1098/rspb.2016.1817

Batchelor TP, Santini G, Briffa M (2012) Size distribution and battles in wood ants: group resource-holding potential is the sum of the individual parts. Anim Behav 83:111-117. https://doi. org/10.1016/j.anbehav.2011.10.014

Bates D, Mächler M, Bolker B, Walker S (2015) Fitting linear mixedeffects models using lme4. J Stat Softw 67:1-48. https://doi. org/10.18637/jss.v067.i01

Bourke AFG, Franks NR (1995) Social evolution in ants. Princeton University Press, Princeton

Bowles S, Gintis H (2011) A cooperative species: human reciprocity and its evolution. Princeton University Press, Princeton

Bruintjes R, Lynton-Jenkins J, Jones JW, Radford AN (2015) Outgroup threat promotes within-group affiliation in a cooperative fish. Am Nat 187:274-282. https://doi.org/10.1086/684411

Burton-Chellew MN, Ross-Gillespie A, West SA (2010) Cooperation in humans: competition between groups and proximate emotions. Evol Hum Behav 31:104-108. https://doi.org/10.1016/j. evolhumbehav.2009.07.005

Cassidy KA, MacNulty DR, Stahler DR et al (2015) Group composition effects on aggressive interpack interactions of gray wolves in Yellowstone National Park. Behav Ecol 26:1352-1360. https ://doi.org/10.1093/beheco/arv081

Choi J, Bowles S (2007) The coevolution of parochial altruism and war. Science 80(318):636-640. https://doi.org/10.1126/scien ce. 1144237

Christensen C, Radford AN (2018) Dear enemies or nasty neighbors? Causes and consequences of variation in the responses of group-living species to territorial intrusions. Behav Ecol 29:1004-1013. https://doi.org/10.1093/beheco/ary010

Cooper MA, Aureli F, Singh M (2004) Between-group encounters among bonnet macaques (Macaca radiata). Behav Ecol Sociobiol 56:217-227. https://doi.org/10.1007/s00265-004-0779-4

Cords M (2002) Friendship among adult female blue monkeys (Cercopithecus mitis). Behaviour 139:291-314. https://doi. org/10.1163/156853902760102681

Darwin C (1871) The descent of man and selection in relation to sex. John Murray, London

Engqvist L (2005) The mistreatment of covariate interaction terms in linear model analyses of behavioural and evolutionary ecology studies. Anim Behav 70:967-971. https://doi.org/10.1016/j. anbehav.2005.01.016

Esponda F, Gordon DM (2015) Distributed nestmate recognition in ants. Proc R Soc B Biol Sci. https://doi.org/10.1098/ rspb.2014.2838

Forstmeier W, Schielzeth H (2011) Cryptic multiple hypotheses testing in linear models: overestimated effect sizes and the winner's curse. Behav Ecol Sociobiol 65:47-55. https://doi.org/10.1007/ s00265-010-1038-5

Guerrieri FJ, Nehring V, Jørgensen CG et al (2009) Ants recognize foes and not friends. Proc R Soc B Biol Sci 276:2461-2468. https://doi.org/10.1098/rspb.2008.1860

Harrison XA (2014) Using observation-level random effects to model overdispersion in count data in ecology and evolution. PeerJ 2:e616. https://doi.org/10.7717/peerj.616

Harrison XA (2015) A comparison of observation-level random effect and Beta-Binomial models for modelling overdispersion in Binomial data in ecology \& evolution. PeerJ 3:e1114. https ://doi.org/10.7717/peerj.1114
Hölldobler B, Wilson EO (1990) The ants. Harvard University Press, Cambridge

Hothorn T, Bretz F, Westfall P (2008) Simultaneous inference in general parametric models. Biom J 50:346-363. https://doi. org/10.1002/bimj.200810425

Hothorn T, Bretz F, Westfall P, et al (2016) multcomp: Simultaneous inference in general parametric models. $\mathrm{R}$ package version 1.4-4

Hsu Y, Earley RL, Wolf LL (2006) Modulation of aggressive behaviour by fighting experience: mechanisms and contest outcomes. Biol Rev Camb Philos Soc 81:33-74. https://doi.org/10.1017/ S146479310500686X

Kavaliers M, Choleris E (2017) Out-group threat responses, in-group bias, and nonapeptide involvement are conserved across vertebrates: (A Comment on Bruintjes et al., "Out-Group Threat Promotes Within-Group Affiliation in a Cooperative Fish"). Am Nat. https://doi.org/10.1086/690838

Langen TA, Tripet F, Nonacs P (2000) The red and the black: habituation and the dear-enemy phenomenon in two desert Pheidole ants. Behav Ecol Sociobiol 48:285-292. https://doi.org/10.1007/ s002650000223

Lehmann L (2011) The demographic benefits of belligerence and bravery: defeated group repopulation or victorious group size expansion? PLoS One 6:e21437. https://doi.org/10.1371/journ al.pone. 0021437

Lehmann L, Feldman MW (2008) War and the evolution of belligerence and bravery. Proc R Soc B Biol Sci 275:2877-2885. https ://doi.org/10.1098/rspb.2008.0842

Majolo B, de Bortoli Vizioli A, Lehmann J (2016) The effect of intergroup competition on intragroup affiliation in primates. Anim Behav 114:13-19. https://doi.org/10.1016/j.anbeh av.2016.01.009

Monclús R, Saavedra I, de Miguel J (2014) Context-dependent responses to neighbours and strangers in wild European rabbits (Oryctolagus cuniculus). Behav Processes 106:17-21. https:// doi.org/10.1016/j.beproc.2014.04.004

Mundry R, Nunn CL (2009) Stepwise model fitting and statistical inference: turning noise into signal pollution. Am Nat 173:119123. https://doi.org/10.1086/593303

Newey PS, Robson SKA, Crozier RH (2010) Know thine enemy: why some weaver ants do but others do not. Behav Ecol 21:381386. https://doi.org/10.1093/beheco/arp201

Okasha S (2006) Evolution and the levels of selection. Oxford University Press, Oxford

Passera L, Roncin E, Kaufmann B, Keller L (1996) Increased soldier production in ant colonies exposed to intraspecific competition. Nature 379:630-631

Polizzi di Sorrentino E, Schino G, Massaro L et al (2012) Betweengroup hostility affects within-group interactions in tufted capuchin monkeys. Anim Behav 83:445-451. https://doi. org/10.1016/j.anbehav.2011.11.016

R Development Core Team (2016) R: A language and environment for statistical computing

Radford AN (2008) Type of threat influences postconflict allopreening in a social bird. Curr Biol 18:114-115. https://doi. org/10.1016/j.cub.2007.12.025

Radford A (2011) Preparing for battle? Potential intergroup conflict promotes current intragroup affiliation. Biol Lett 7:26-29. https ://doi.org/10.1098/rsbl.2010.0507

Radford AN, Majolo B, Aureli F (2016) Within-group behavioural consequences of between-group conflict: a prospective review. Proc R Soc B Biol Sci 283:20161567. https://doi.org/10.1098/ rspb.2016.1567

Reeve HK, Holldobler B (2007) The emergence of a superorganism through intergroup competition. Proc Natl Acad Sci 104:97369740. https://doi.org/10.1073/pnas.0703466104 
Robinson EJH, Barker JL (2017) Inter-group cooperation in humans and other animals. Biol Lett 13:20160793. https://doi. org/10.1098/rsbl.2016.0793

Rose GJ, Brenowitz EA (1997) Plasticity of aggressive thresholds in Hyla regilla: discrete accommodation to encounter calls. Anim Behav 53:353-361

Roulston TH, Buczkowski G, Silverman J (2003) Nestmate discrimination in ants: effect of bioassay on aggressive behavior. Insectes Soc 50:151-159. https://doi.org/10.1007/s0004 0-003-0624-1

Schino G (2007) Grooming and agonistic support: a meta-analysis of primate reciprocal altruism. Behav Ecol 18:115-120. https://doi. org/10.1093/beheco/ar1045

Stroeymeyt N, Grasse AV, Crespi A et al (2018) Social network plasticity decreases disease transmission in a eusocial insect. Science 80(362):941-945. https://doi.org/10.1126/science.aat4793

Sturgis SJ, Gordon DM (2013) Aggression is task dependent in the red harvester ant (Pogonomyrmex barbatus). Behav Ecol 24:532-539. https://doi.org/10.1093/beheco/ars194

Tanner CJ, Keller L (2012) Nest distribution varies with dispersal method and familiarity-mediated aggression for two sympatric ants. Anim Behav 84:1151-1158. https://doi.org/10.1016/j.anbeh av.2012.08.018

Thomas ML, Payne-Makrisâ CM, Suarez AV et al (2007) Contact between supercolonies elevates aggression in Argentine ants. Insectes Soc 54:225-233. https://doi.org/10.1007/s0004 0-007-0935-8

Thompson FJ, Cant MA (2018) Dynamic conflict among heterogeneous groups: a comment on Christensen and Radford. Behav Ecol 00:1-2. https://doi.org/10.1093/beheco/art055

van Wilgenburg E, Elgar MA (2013) Confirmation bias in studies of nestmate recognition: a cautionary note for research into the behaviour of animals. PLoS One 8:1-8. https://doi.org/10.1371/ journal.pone.0053548

Van Wilgenburg E, Clémencet J, Tsutsui ND (2010) Experience influences aggressive behaviour in the Argentine ant. Biol Lett 6:152155. https://doi.org/10.1098/rsbl.2009.0616

Whittingham MJ, Stephens PA, Bradbury RB, Freckleton RP (2006) Why do we still use stepwise modelling in ecology and behaviour? J Anim Ecol 75:1182-1189. https://doi.org/10.111 1/j.1365-2656.2006.01141.x

Wilson ML, Hauser MD, Wrangham RW (2001) Does participation in intergroup conflict depend on numerical assessment, range location, or rank for wild chimpanzees? Anim Behav 61:1203-1216. https://doi.org/10.1006/anbe.2000.1706 